\title{
105 \\ POSTERIOR ONLY SURGERY FOR RIGID SCOLIOTIC CURVES PROGRESSED ABOVE 80 DEGREES: DOES IT YIELD SUFFICIENT CORRECTION?
}

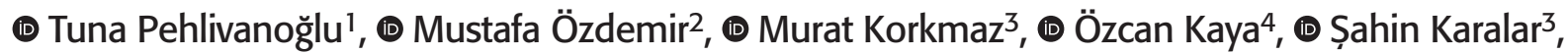 \\ (1) Turgut Akgül3, (1) Fatih Dikici5

\begin{abstract}
${ }^{1}$ Emsey Hospital, Advanced Spine Surgery Center, Clinic of Orthopaedic Surgery and Traumatology; Yeni Yüzyıl University Faculty of Health Sciences, istanbul, Turkey

3 Istanbul University, İstanbul Faculty of Medicine, Department of Orthopaedic Surgery and Traumatology, Istanbul, Turkey

${ }^{4}$ University of Health Sciences Turkey, Istanbul Training and Research Hospital, Clinic of Orthopaedic Surgery and Traumatology, İstanbul, Turkey

${ }^{5}$ Acıbadem University Faculty of Medicine, Department of Orthopaedic Surgery and Traumatology, Istanbul Turkey
\end{abstract} \\ 2Kahramanmaraş Sütçü Imam University Faculty of Medicine, Department of Orthopaedic Surgery and Traumatology, Kahramanmaraş, Turkey
}

\begin{abstract}
Objective: The aim of this study was to present the long-term results of posterior spinal fusion (PSF) with pedicle screws only for rigid large thoracic curves by questioning, whether this approach could yield sufficient radiographic correction together with good clinical outcomes.

Materials and Methods: Patients, who had rigid large thoracic curves and underwent PSF with pedicle screws only between 1993 and 2016 in a single center were retrospectively reviewed. Patients were radiographically evaluated by using standard posteroanterior whole body standing $X$-rays and side bending X-rays. Functional evaluation was performed by using SRS-22 scores.

Results: Fifty-eight patients with an average age of 16.7 and an average follow-up duration of 131.6 months were included. Rigid scoliotic curves of the study population were further subcategorized as: idiopathic $(n=50)$, congenital $(n=6)$, and neuromuscular $(n=2)$ with an average flexibility of $21.7 \%$. Average number of fused segments was 14.2. Patients had an average pre-operative major curve magnitude of $96^{\circ}\left(\right.$ range; $82^{\circ}-122^{\circ}$ ) which was improved to $28^{\circ}$ (range; $\left.16^{\circ}-52^{\circ}\right)(p<0.001)$ at the last follow-up visit. An average pre-operative shoulder asymmetry of $3.2 \mathrm{~cm}$ in 23 patients was improved to $0.7 \mathrm{~cm}$ ( $p<0.001$ ). An average pre-operative pelvic asymmetry of $3.6 \mathrm{~cm}$ in 16 patients was improved to $1.0 \mathrm{~cm}$ ( $p<0.001)$. Total SRS scores and the scores of all of SRS domains were noted to be improved significantly at the last follow-up.

Conclusion: Rigid thoracic scoliotic curves could be corrected with PSF with pedicle screws only, with high success and low rates of complications. By utilizing PSF to rigid thoracic curves, the possible complications of anterior surgery could be avoided, while highly successful clinical and functional outcomes could be obtained in the long-term.

Keywords: Rigid thoracic curves, posterior spinal fusion, pedicle screws, thoracic spine, curve magnitudes, functional scores
\end{abstract}

\section{INTRODUCTION}

A large and rigid scoliotic curve was defined as a curve with a magnitude of 70 degrees or above and a curve flexibility of $30 \%$ or below ${ }^{(1,2)}$. While the current gold standard treatment modality for idiopathic curves progressed beyond $45^{\circ}$ is the posterior spinal fusion (PSF) with segmental instrumentation by using pedicle screws, the optimal treatment modality for a rigid large curve is still a controversy ${ }^{(3-5)}$.

Traditionally for rigid large thoracic scoliotic curves, anterior release combined with PSF has been accepted as the standard surgical option ${ }^{(6-8)}$. However, high general complication rate of the combined surgery, in addition to its negative impact on pulmonary functions as a result of chest wall violation has also been underlined by many studies ${ }^{(9-11)}$.

The concept of thoracic pedicle screws (TPS), that was introduced by Suk et al. ${ }^{(12)}$, confirmed by many other studies to provide improved segmental fixation, better immediate correction of both sagittal and coronal planes, allowing shorter segments of fusion and possesing lower risks for any neurological damage as applied to Lenke type 1 and 2 thoracic curves below $70^{\circ(13-15)}$. 
For rigid large thoracic curves, recent studies underlined the safety and correctional efficacy of posterior only approaches utilizing pedicle screws as compared to combined surgeries while questioning the rationale behind conducting the anterior procedure with potential complications together with the surgical burden and concluding that only posterior surgery could be enough for the sufficient correction of the rigid large thoracic curves ${ }^{(6-8,16)}$.

The aim of this study was to present the long-term results of PSF with pedicle screws only for rigid large thoracic curves by questioning, whether this approach could yield sufficient radiographic correction together with good clinical outcomes.

\section{MATERIALS AND METHODS}

After obtaining institutional review board approval (İstanbul University, İstanbul Faculty of Medicine, Department of Orthopedic Surgery and Traumatology, approval number: 2021/191), a retrospective analysis was undertaken to detect a consecutive group of patients with scoliosis and rigid thoracic curves, that were operated in a single institution between 19932016. One hundred-two consecutive patients were detected to be operated (anterior only, anterior-posterior combined, posterior only) in the aforementioned time interval in a single institution for the management of rigid thoracic curves.

Patients were enrolled in the present study on the basis of the following inclusion criteria: (1) Having been operated posteriorly with pedicle screws only; (2) having a large-rigid thoracic curve as the major curve with a magnitude of $>80^{\circ}$ (measured in standing PA X-rays) and flexibility of $<30 \%$ (measured in side-bending) $\mathrm{X}$-rays; (3) being a primary case (not a revision), (4) having an apical vertebra above T12, (5) having a minimum follow-up duration of 5 years (Table 1 ).

Exclusion criteria comprised: (1) Having been operated anteriorly/with combined procedures/posteriorly by hybrid systems (hooks, wires, etc.); (2) having a large-flexible thoracic curve as the major curve with a magnitude of $>80^{\circ}$ (measured in standing PA X-rays) and flexibility of $>30 \%$ (measured in side-bending X-rays) or vice versa; (3) being a revision case, (4) having an apical vertebra below T12, (5) having a minimum follow-up duration of less than 5 years. As a result of the exclusion criteria 44 patients (2: Anterior surgery, 5: Combined anterior-posterior surgery, 23: Posterior hybrid surgery with hooks and wires, 4: Age $>17.3$ : Rigid thoracic curve $<80^{\circ}, 2$ : Large thoracic curves with a flexibility $>30 \%, 3$ : Revision cases operated elsewhere, 1: Apical vertebra above T12, 1: Unwilling to participate) were excluded from the study. The remaining 58 patients were included in the study (Table 2).

\section{Radiographic Outcome Parameters (ROP)}

Preoperative and postoperative radiographic measurements were undertaken on standing whole spine $\mathrm{X}$-rays, while the flexibilities of the curves were calculated on both side bending $\mathrm{X}$-rays. ROP were composed of the rigid major thoracic curve magnitude in the coronal plane, thoracic kyphosis (T5-12), shoulder asymmetry and pelvic asymmetry.

The radiographic measurements were undertaken by one independent senior spine surgeon with Surgimap software (Nemaris Inc., New York, NY, USA) to prevent any bias of multiple observes. The radiographs were obtained as standing whole spine $\mathrm{X}$-rays in PA and Lateral standard position. $\mathrm{X}$-rays were taken preoperatively, immediate postoperatively, at the $1^{\text {st }}$ (first outpatient visit), $3^{\text {rd }}$ and $6^{\text {th }}$ month, annually and at the latest FU appointment.

\section{Clinical Outcome Parameters (COP)}

As patient reported outcome questionnaires SRS-22 scores were applied to evaluate the clinical and functional outcome.

\section{Surgical Technique}

Patients were placed in prone position. A midline skin incision followed by subperiosteal dissection of paraspinal muscles were undertaken. Pedicle screws were inserted by utilizing

Table 2. Flowchart of the study population

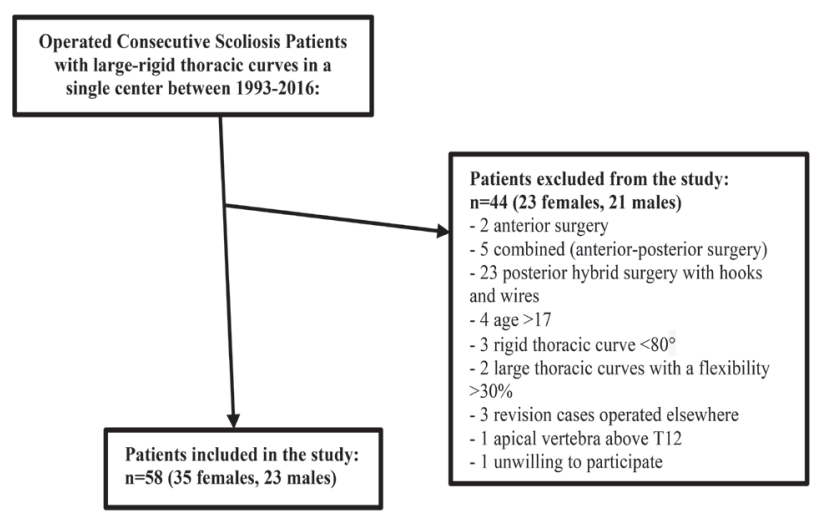

Table 1. Inclusion and exclusion criteria

Inclusion Criteria
Operated posteriorly with pedicle screws only

Having a large-rigid thoracic curve as the major curve with a magnitude of $>80^{\circ}$ (measured in standing PA) and flexibility of $<30 \%$ (measured in side bending)

Being a primary case (not a revision)

An apical vertebra above T12

A minimum follow-up duration of 5 years

\section{Exclusion Criteria}

Operated anteriorly/with hybrid systems/posteriorly by hybrid systems (hooks, wires, etc.)

Having a large-flexible thoracic curve as the major curve with a magnitude of $>80^{\circ}$ (measured in standing PA) and flexibility of $>30 \%$ (measured in side bending) or vice versa

Being a revision case

An apical vertebra below T12

A minimum follow-up duration of less than 5 years 
free hand technique as Kim et al.(13) described, followed by the development of the pedicle trajectory and confirmation of the intraosseous borders. A 1.0-mm smaller diameter tapping than the diameter of the intended screw was performed to enhance the fixational stability ${ }^{(17)}$. After the placement of pedicle screws, the intraosseous screw trajectories were checked and confirmed by using fluoroscopy in both planes. Likewise, after the placement of rods, application of the correctional maneuvers and placement of set screws, the corrections and coronal-sagittal alignments were checked and confirmed by using fluoroscopy in both planes, as well. Inferior articular facets were removed by using an osteotome or rongeur to provide fusion, which was augmented by using local bone grafts harvested from facet joints and spinous processes. None of the patients required allografts or any bone substitute. Additionally apical Smith-Petersen osteotomies were performed for curves above $110^{\circ}$ on the standing whole spine posteroanterior $X$-rays or for residual curves $>90^{\circ}$ on side bending X-rays.

\section{Postoperative Rehabilitation Protocol}

Patients were mobilized immediately after surgery and were allowed to return to daily activities after discharge, while return to sportive activities (including non-contact sports, swimming and light gym) were allowed after $6^{\text {th }}$ post-operative month.

\section{Information of Informed Consent}

All patients were taken informed consents, so that their pre, intra- and postoperative data including the $X$-rays could be used for publication by hiding their identity.

\section{Statistical Analysis}

For the statistical analysis, SPSS software (Version 22.0; SPSS Inc, Chicago, IL, USA) was used. Data are expressed as mean \pm standard deviation. The chi-square test and Fisher's Exact test were used for the analysis of categorical variables and to compare different time points where appropriate. One-Way ANOVA test was used to determine a significant difference at various time points. A p-value less than 0.05 was considered as statistically significant.

\section{RESULTS}

Fifty-eight patients (35 females, 23 males) with an average age of 16.7 (range 12-42) and an average follow-up duration of 131.6 months (range 60-174) were included. Scoliotic curves of the study population were further subcategorized as: Fifty idiopathic (2 infantile, 8 juvenile, 26 adolescent, 14 adult), 6 congenital, 2 neuromuscular and also associated increased thoracic kyphosis in 21 patients. These curves had an average flexibility of $21.7 \%$ (range 11.4-26.8). They all had an apex of deformity above T12. Average number of fused segments was 14.2 (range 11-16). A thoracoplasty was undertaken in 19 patients. Patients had an average duration of operations of 317.4 min (range 184-360) and an average post-operative hospital stay of 3.6 days (range $3-7$ ) (Table 3 ).

Patients had an average pre-operative major curve magnitude of $96^{\circ}$ (range; $82^{\circ}-122^{\circ}$ ) was improved with high statistical significance to $28^{\circ}\left(\right.$ range $\left.; 6^{\circ}-52^{\circ}\right)(p<0.001)$ at the last followup visit. The rate of correction was calculated as $70.8 \%$. Twentythree patients' average preoperative shoulder asymmetry of 3.2 $\mathrm{cm}$ was improved to $0.7 \mathrm{~cm}$ in 11 patients $(p<0.001)$ with high statistical significance, while the other 12 patients were not detected to have shoulder asymmetry. Similarly, an average preoperative pelvic asymmetry of $3.6 \mathrm{~cm}$ in 16 patients was improved to $1.0 \mathrm{~cm}$ in 10 patients $(p<0.001)$ with high statistical significance, while the other 5 patients were not detected to have pelvic asymmetry. Patients had an average pre-operative thoracic kyphosis (T5-T12) of $49^{\circ}$ (range; $7^{\circ}-74^{\circ}$ ), while it was improved post-operatively to $33^{\circ}$ (range; $\left.23^{\circ}-48^{\circ}\right)(p=0.024)$ (Table 4, Figure 1,2).

After the availability of the Turkish validated version of SRS22 score questionnaire, it was applied to 26 patients preoperatively and at the last follow-up appointment. They had an average preoperative total SRS score of 3.2 (Function: 3.2, pain: 3.6, self image: 2.8, mental health: 3.7, satisfaction: 2.9 ), which improved to 4.5 (Function: 4.4, pain: 4.2, self image: 4.8 , mental health: 4.8, satisfaction: 4.1$)(p<0.001$ for total, $p<0.001$ for each domain) with high statistical significance (Table 4).

Table 3. Data regarding the patients' demographics, curves and levels of instrumentation

\begin{tabular}{ll}
\hline Number of patients & 58 (35 females, 23 males) \\
\hline Average age of patients & 16.7 (range 12-42) \\
\hline Average duration of follow-up & 131.6 (range 60-174) \\
\hline & $\begin{array}{l}50 \text { idiopathic (2 infantile, } 8 \text { juvenile, } 26 \text { adolescent, } 14 \text { adult) } \\
6 \text { congenital } \\
2 \text { neuromuscular } \\
\text { Types of scoliotic curves }\end{array}$ \\
\hline Avsociated increased thoracic kyphosis in 21 patients \\
\hline Average number of instrumented levels & $21.7(11.4-26.8)$ \\
\hline Most proximally instrumented level & $14.2(11-16)$ \\
\hline Most distally instrumented level & T1 \\
\hline Average duration of operations & L4 \\
\hline Average postoperative hospital stay & 317.4 (range 184-360) \\
\hline
\end{tabular}


Table 4. Radiographic, clinical and functional outcomes

\begin{tabular}{|c|c|c|c|}
\hline & Preoperative & At the last follow-up & p-value \\
\hline Average major curve magnitude & $96^{\circ}\left(82^{\circ}-122^{\circ}\right)$ & $28^{\circ}\left(\right.$ range $\left.16^{\circ}-52^{\circ}\right)$ & $<0.001$ \\
\hline Average thoracic kyphosis (T5-T12) & $49^{\circ}\left(\right.$ range $\left.7^{\circ}-74^{\circ}\right)$ & $33^{\circ}$ (range $\left.23^{\circ}-48^{\circ}\right)$ & 0.024 \\
\hline Average pelvic asymmetry & 3.6 cm (16 patients) & $1.0 \mathrm{~cm}$ (10 patients) & $<0.001$ \\
\hline $\begin{array}{l}\text { Average total SRS scores (Average domain } \\
\text { scores) for } 26 \text { patients }\end{array}$ & $\begin{array}{l}\text { Total: } 3.2 \\
\text { Function: } 3.2 \\
\text { Pain: } 3.6 \\
\text { Self image: } 2.8 \\
\text { Mental health: } 3.7 \\
\text { Satisfaction: } 2.9\end{array}$ & $\begin{array}{l}\text { Total: } 4.5 \\
\text { Function: } 4.4 \\
\text { Pain: } 4.2 \\
\text { Self image: } 4.8 \\
\text { Mental health: } 4.8 \\
\text { Satisfaction: } 4.1\end{array}$ & $\begin{array}{l}<0.001 \\
<0.001 \text { for every } \\
\text { domain }\end{array}$ \\
\hline
\end{tabular}

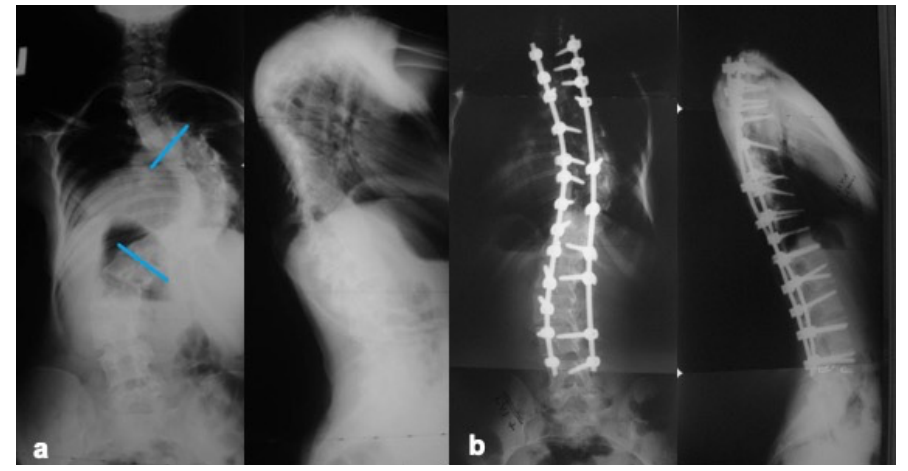

Figure 1. A 15 years old female with a ridig throracic curve of $95^{\circ}$ reduced to $19^{\circ}$. A: Standing preoperative whole spine posteroanterior and lateral X-rays. B: Standing whole spine posteroanterior and lateral X-rays at the last follow-up

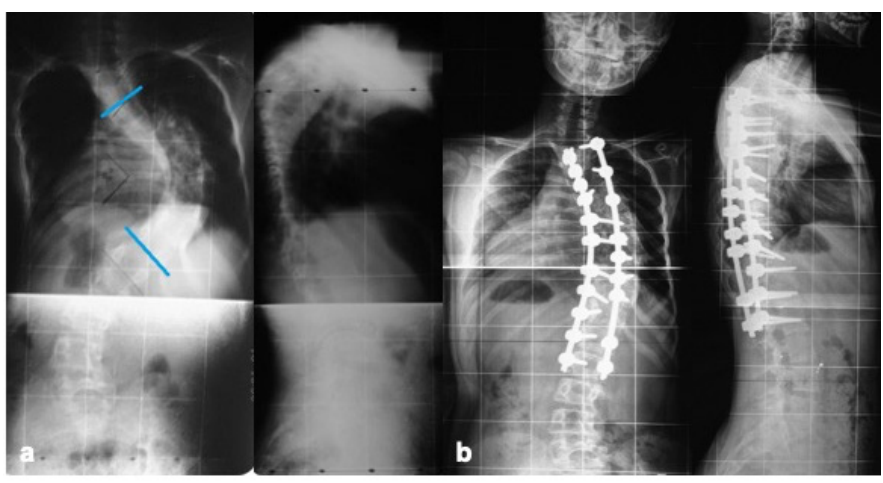

Figure 2. A 14 years old female with a rigid thoracic curve of $101^{\circ}$ reduced to $26^{\circ}$. A: Standing pre-operative whole spine posteroanterior and lateral X-rays. B: Standing whole spine posteroanterior and lateral $\mathrm{X}$-rays at the last follow-up

No infectious, neurologic or implant related complication was noted. Two patients were noted to have superficial wound side infections resolved with medical treatment. Two other patients were detected to have fever due to atelectasis immediate postoperatively and were treated with medication and respiratoy physiotherapy post operatively. A complication rate of $6.8 \%$ was acquired. No other major complications were noted. No revision surgery was performed to any patient in this particular cohort during the entire follow-up period.

\section{DISCUSSION}

The criterion to define a severe rigid scoliosis in addition to a diminished curve flexibility $(<30 \%)$ was a Cobb angle $>80^{\circ}$ in by many studies ${ }^{(18-20)}$, and $>90^{\circ}$ by other studies ${ }^{(21,22)}$, and even $>100^{\circ}$ by another study ${ }^{(2)}$. Our criterion to define a large-rigid curve was also in conjunction with the studies, that accepted a Cobb angle as $>80^{\circ}$ and a curve flexibility $<30 \%$.

Historically, for rigid and large thoracic curves, in order to overcome the correctional inferiority and problems in thoracic spine associated with posterior instrumentation performed with hooks, anterior releases were advised to increase the curve flexibility resulting in greater correction and increased surface area for fusion expected to occur in future ${ }^{(23-25)}$. As a result of that principle, anterior release combined with PSF (APSF) became the traditional management strategy for large rigid curves, despite the fact that anterior surgery was associated with many complications including major pulmonary problems, increased time under general anesthesia and increased patient costs $8,8,24,26)$. This is the main reason, why the authors of the present study mostly avoided applying anterior surgery and preferred posterior spinal instrumentation as shown (2 anterior, 5 antero-posterior approaches vs 81 posterior only approaches). TPS gained recently popularity because of providing three column fixation, improved correction of the curves in sagittal and coronal planes, being able to achieve great rotational correction together with lower rates of pseudoarthrosis, implant failure and need for postoperative bracing ${ }^{(14,15,27)}$. The placement of TPS were reported to be highly accurate, safe and successful despite the abnormal anatomy and orientation of the pedicles belonging to a severe rigid curve of a deformed spine of any patient without any neurological complications with more than $98 \%$ of precision in technique ${ }^{(28,29)}$. As a result of the aforementioned data, authors of the present study nearly always prefer to perform posterior only approaches by using pedicle screws only.

Despite many associated complications and risks, the correctional success of APSF reported many times (Kandwal et al.(2): 77.2\%, Bullmann et al. ${ }^{(19)} 67 \%$ ). However, it was recently shown by Luhmann et al. ${ }^{(8)}$, that PSF undertaken with pedicle 
screws only to rigid thoracic curves was able to yield equal correction as compared to antero-posterior combined surgery. This conclusion was supported by other comparative studies, so that posterior only approaches were encouraged ${ }^{(7,15)}$.

Luhmann et al. ${ }^{(8)}$ in their comparative study of 84 patients with minimum follow-up duration of 2 years created two matched groups of patients with APSF and PSF. APSF and PSF with TPS group was found out to yield $48.3^{\circ}-47.5^{\circ}$ of coronal correction with no statistical significance; in other words the improvement in rigid thoracic curve was not statistically significant. They reported a correction rate of $58.3 \%$. The present study reported $68^{\circ}$ of correction with a correctional rate of $70.8 \%$ underlining the correctional efficiacy of posterior only surgery with TPS. Luhmann et al.(8) also underlined, that over the last years for rigid curves above $70^{\circ}$ they were always applying PSF with TPS only, because TPS could obviate the need for anterior surgery together with additional surgical procedural charge and total costs in addition to prevent from increased morbidity caused by chest wall violation of the anterior surgery.

Dobbs et al.(15) also underlined in his comparative study of 54 patients with rigid thoracic curves, that were applied either APSF or PSF with pedicle screws, that for rigid curves $>90^{\circ} \mathrm{PSF}$ undertaken with pedicle screws provided the same coronal and sagittal correction as that with APSF. They reported, that both groups had a correctional rate of 44\% (APSF: Mean preoperative Cobb: 92.3 , Cobb at the last follow-up: $55^{\circ}$, PSF: Mean preoperative Cobb: $94.3^{\circ}$, Cobb at the last follow-up: $\left.56^{\circ}\right)$. In the present study PSF with TPS only was found out to improve the mean preoperative Cobb angle of $96^{\circ}$ to $28^{\circ}$. Dobbs et al. ${ }^{(15)}$ reported similar mean thoracic T5-T12 angles of PSF group pre-operatively and at the last follow-up. The present study reported that the mean thoracic kyphosis was improved from $49^{\circ}$ preoperatively to $33^{\circ}$ at the latest follow-up visit with low statistical significance.

Dobbs et al. ${ }^{(15)}$ underlined that patients with rigid large thoracic curves already had significant restrictive pulmonary problems and ABSF should be avoided in that particular group to prevent from further declines in pulmonary functions, hence the PSF with TPS only was advised as a wiser choice, since it was able to yield the same correctional efficacy without creating further pulmonary problems. This is a very important point that we totally agreed upon.

The surgical technique by using free hand pedicle screw placement is similar to the techniques described in the studies of Luhmann et al. ${ }^{(8)}$ and Dobbs et al.(15). Dobbs et al. ${ }^{(15)}$ and Luhmann et al. ${ }^{(8)}$ reported neither any reoperation nor any implant related or neurologic complication besides the pulmonary complications associated with the APSF. The present study in conjunction with the aforementioned studies also reported neither any reoperation or any implant related or neurologic complication.

Shi et al. ${ }^{(7)}$ also reported in their comparative study comprising patients with rigid thoracic curves, that were applied APSF or PSF with TPS only, that posterior only approach with all pedicle screws was able to provide the same curve correction as APSF without carrying any potential risks of anterior surgery. Similar to the present study, they utilized the SRS-22 scores pre- and postoperatively and detected significant improvement in total score and in all domains. Out results were in conjunction with that data, so that our patient population was also detected to have highly significant improvement in total SRS scores and also in every domain individually. Besides Shi et al.(7) reported an average duration of operations of 420 mins for PSF and an average of 4 days of hospital stay. The present study reported an average duration of operations of 317.4 mins for PSF, which was lower than Shi's data and an average of 3.6 days of hospital stay similar to Shi's data.

Coe et al.(11) utilized the morbidity and mortality database of Scoliosis Research Society (SRS), that contained 58,197 cases that were applied either anterior, or posterior or combined spinal fusion. He reported that as compared to posterior or anterior surgery alone, the anterior posterior combined surgery was doubling the rate of complications, while the combined surgery also was associated with a significantly higher rate of neurological complications ${ }^{(11)}$. In conjunction with Coe et al. ${ }^{(11)}$ data, the authors of the present study avoided utilizing APSF, but performing PSF with pedicle screws only.

\section{Study Limitations}

This study comprises some limitations. The first one was the lack of a control group, who were applied APSF. But as reported in the flowchart, APSF was avoided as much as possible as a result of its potential serious complications and the high correctional efficacy of TPS applied with PSF. Another limitation was the limited number of patients, that were owed to the strict inclusion criteria. Another limitation was that SRS22 score was not applied to all patients, but only to those after the validated Turkish version was available. This was owed to the long follow-up duration of the present study.

\section{CONCLUSION}

The present study concluded, that as a result of PSF undertaken with pedicle screws only, rigid thoracic scoliotic curves could be corrected with high success and low rates of complications. By utilizing PSF to rigid thoracic curves the possible complications of anterior surgery could be avoided, while highly successful clinical and functional outcomes could be obtained in the long term.

\section{Ethics}

Ethics Committee Approval: Institutional review board approval was taken İstanbul University İstanbul Faculty of Medicine, Department of Orthopedic Surgery and Traumatology (approval number: 2021/191).

Informed Consent: All patients were taken informed consents.

\section{Authorship Contributions}

Surgical and Medical Practices: T.P., M.Ö., M.K., Ö.K., Ş.K., T.A., F.D., Design: T.P., T.A., Data Collection or Processing: T.P., 
Analysis or Interpretation: T.P., M.Ö., M.K., Ö.K., Ş.K., T.A., F.D., Literature Search: T.P., T.A., Writing: T.P.

Financial Disclosure: The authors declared that this study received no financial support.

Conflict of Interest: The authors have no conflicts of interest to declare.

\section{REFERENCES}

1. Chang KW. Cantilever bending technique for treatment of large and rigid scoliosis. Spine (Phila Pa 1976). 2003;28:2452-8.

2. Kandwal P, Goswami A, Vijayaraghavan G, Subhash KR, Jaryal $A$, Upendra BN, et al. Staged anterior release and posterior instrumentation in correction of severe rigid scoliosis (Cobb Angle >100 Degrees). Spine Deform. 2016;4:296-303.

3. Weinstein SL, Dolan LA, Cheng JCY, Danielsson A, Morcuende JA. Adolescent idiopathic scoliosis. Lancet (London, England). 2008;371:1527-37.

4. Aubin $\mathrm{CE}$, Labelle $\mathrm{H}$, Ciolofan OC. Variability of spinal instrumentation configurations in adolescent idiopathic scoliosis. Eur Spine J. 2007; 16:57-64.

5. de Kleuver M, Lewis SI, Germscheid NM, Kamper SI, Alanay A, Berven $\mathrm{SH}$, et al. Optimal surgical care for adolescent idiopathic scoliosis: an international consensus. Eur Spine J. 2014;23:2603-18.

6. Arlet $\mathrm{V}$, Jiang $\mathrm{L}$, Ouellet J. Is there a need for anterior release for $70-90$ degrees masculine thoracic curves in adolescent scoliosis? Eur Spine J. 2004; 13:740-5.

7. Shi Z, Chen J, Wang C, Li M, Li Q, Zhang Y, et al. Comparison of thoracoscopic anterior release combined with posterior spinal fusion versus posterior-only approach with an all-pedicle screw construct in the treatment of rigid thoracic adolescent idiopathic scoliosis. J Spinal Disord Tech. 2015;28:E454-9. doi: 10.1097/ BSD.0b013e3182a2658a.

8. Luhmann SI, Lenke LG, Kim YJ, Bridwell KH, Schootman M. Thoracic adolescent idiopathic scoliosis curves between 70 degrees and 100 degrees: is anterior release necessary? Spine (Phila Pa 1976). 2005;30:2061-7.

9. Lenke LG, Newton PO, Marks MC, Blanke KM, Sides B, Kim $\mathrm{YJ}$, et al. Prospective pulmonary function comparison of open versus endoscopic anterior fusion combined with posterior fusion in adolescent idiopathic scoliosis. Spine (Phila Pa 1976). 2004;29:2055-60.

10. Kim YJ, Lenke LG, Bridwell KH, Kim KL, Steger-May K. Pulmonary function in adolescent idiopathic scoliosis relative to the surgical procedure. J Bone Joint Surg Am. 2005;87:1534-41.

11. Coe JD, Arlet V, Donaldson W, Berven S, Hanson DS, Mudiyam R, et al. Complications in spinal fusion for adolescent idiopathic scoliosis in the new millennium. A report of the Scoliosis Research Society Morbidity and Mortality Committee. Spine (Phila Pa 1976). 2006;31:345-9.

12. Suk SI, Lee CK, Kim WJ, Chung YJ, Park YB. Segmental pedicle screw fixation in the treatment of thoracic idiopathic scoliosis. Spine (Phila Pa 1976). 1995;20:1399-405.

13. Kim YJ, Lenke LG, Bridwell KH, Cho YS, Riew KD. Free hand pedicle screw placement in the thoracic spine: is it safe? Spine (Phila $\mathrm{Pa}$ 1976). 2004;29:333-42; discussion 342.
14. Suk SI, Kim WJ, Lee SM, Kim JH, Chung ER. Thoracic pedicle screw fixation in spinal deformities: are they really safe? Spine (Phila Pa 1976). 2001;26:2049-57.

15. Dobbs MB, Lenke LG, Kim YJ, Luhmann SJ, Bridwell KH. Anterior/ posterior spinal instrumentation versus posterior instrumentation alone for the treatment of adolescent idiopathic scoliotic curves more than 90 degrees. Spine (Phila Pa 1976). 2006;31:2386-91.

16. Lee CS, Park SJ, Chung SS, Kang KC, Jung CH, Kim YT. A comparative study between thoracoscopic surgery and posterior surgery using allpedicle-screw constructs in the treatment of adolescent idiopathic scoliosis. J Spinal Disord Tech. 2013;26:325-33.

17. Kuklo TR, Lehman RAJ. Effect of various tapping diameters on insertion of thoracic pedicle screws: a biomechanical analysis. Spine (Phila Pa 1976). 2003;28:2066-71.

18. Yamin S, Li L, Xing W, Tianjun G, Yupeng Z. Staged surgical treatment for severe and rigid scoliosis. J Orthop Surg Res. 2008;3:26.

19. Bullmann V, Halm HFH, Schulte T, Lerner T, Weber TP, Liljenqvist UR. Combined anterior and posterior instrumentation in severe and rigid idiopathic scoliosis. Eur Spine J. 2006;15:440-8.

20. Suk SI, Chung ER, Kim JH, Kim SS, Lee IS, Choi WK. Posterior vertebral column resection for severe rigid scoliosis. Spine (Phila Pa 1976). 2005;30:1682-7.

21. Shen J, Qiu G, Wang Y, Zhang Z, Zhao Y. Comparison of 1-stage versus 2 -stage anterior and posterior spinal fusion for severe and rigid idiopathic scoliosis--a randomized prospective study. Spine (Phila Pa 1976). 2006;31:2525-8.

22. Zhou C, Liu L, Song Y, Liu H, Li T, Gong Q, et al. Anterior release internal distraction and posterior spinal fusion for severe and rigid scoliosis. Spine (Phila Pa 1976). 2013;38:E1411-7. doi: 10.1097/ BRS.0b013e3182a3cd90.

23. Lenke LG. Anterior endoscopic discectomy and fusion for adolescent idiopathic scoliosis. Spine (Phila Pa 1976). 2003;28(Suppl 15):S3643. doi: 10.1097/01.BRS.0000076896.14492.DC.

24. Arlet V. Anterior thoracoscopic spine release in deformity surgery: a meta-analysis and review. Eur Spine J. 2000;9 (Suppl 1):S17-23. doi: $10.1007 / \mathrm{s} 005860000186$.

25. Newton PO, Marks M, Faro F, Betz R, Clements D, Haher T, et al. Use of video-assisted thoracoscopic surgery to reduce perioperative morbidity in scoliosis surgery. Spine (Phila Pa 1976). 2003;28:S24954. doi: 10.1097/01.BRS.0000092475.04293.F5.

26. Kim Y], Lenke LG, Bridwell KH, Cheh G, Sides B, Whorton J. Prospective pulmonary function comparison of anterior spinal fusion in adolescent idiopathic scoliosis: thoracotomy versus thoracoabdominal approach. Spine (Phila Pa 1976). 2008;33:1055-60.

27. Liljenqvist UR, Halm HF, Link TM. Pedicle screw instrumentation of the thoracic spine in idiopathic scoliosis. Spine (Phila Pa 1976). 1997;22:2239-45.

28. Belmont PJJ, Klemme WR, Dhawan A, Polly DW]. In vivo accuracy of thoracic pedicle screws. Spine (Phila Pa 1976). 2001;26:2340-6.

29. O'Brien MF, Lenke LG, Mardjetko S, Lowe TG, Kong Y, Eck K, et al. Pedicle morphology in thoracic adolescent idiopathic scoliosis: is pedicle fixation an anatomically viable technique? Spine (Phila Pa 1976). 2000;25:2285-93. 